\title{
Electrocardiographic Risk Markers for Heart Failure in Women vs
}

\section{Men}

M. Anette E. Haukilahti, MD a, Tuomas V. Kenttä, PhD a, Jani T. Tikkanen, MD a, Olli Anttonen, MD b, Aapo L. Aro MD c, Tuomas Kerola, MD b, Harri Rissanen, PhD d, Paul Knekt, PhD d, M. Juhani Junttila, Prof a, Heikki V. Huikuri, Prof a

Running title: ECG Risk Markers of Heart Failure

a Research Unit of Internal Medicine, Medical Research Center Oulu, University of Oulu and University Hospital of Oulu, Finland.

b Department of Internal Medicine, Päijät-Häme Central Hospital, Lahti, Finland. c Division of Cardiology Heart and Lung Center, Helsinki University Hospital, Helsinki, Finland. d Finnish National Institute for Health and Welfare, Helsinki, Finland.

Corresponding author:

M Anette E Haukilahti, BM

Research Unit of Internal Medicine, University of Oulu and Oulu University Hospital P.O. box 5000, 90014 University of Oulu, Finland

Tel: +358 449729808, e-mail: anette.haukilahti@gmail.com 


\section{ABSTRACT}

Heart failure (HF) is one of the leading causes of hospitalization in the Western world. Women have a lower HF hospitalization rate and mortality compared to men. The role of electrocardiography as a risk marker of future HF in women is not well known. We studied association of electrocardiographic (ECG) risk factors for HF hospitalization in women from a large middle-aged general population with a long-term follow-up and compared the risk profile to men. Standard 12-lead ECG markers were analyzed from 10,864 subjects (49\% women), and their predictive value for HF hospitalization was analyzed. During the follow-up ( $30 \pm 11$ years), a total of 1,743 subjects had HF hospitalization; of these, 861 were women (49\%). Several baseline characteristics, such as age, body mass index, blood pressure, and history of prior cardiac disease predicted the occurrence of HF both in women and men $(\mathrm{P}<0.001$ for all). After adjusting for baseline variables, ECG sign of left ventricular hypertrophy $(\mathrm{LVH})(\mathrm{P}<0.001)$, and atrial fibrillation $(\mathrm{P}<0.001)$ were the only baseline ECG variables that predicted future HF in women. In men, HF was predicted by fast heart rate $(\mathrm{P}=0.008)$, $\mathrm{T}$-wave inversions $(\mathrm{P}<0.001)$, abnormal $\mathrm{Q}$-waves $(\mathrm{P}=0.002)$, and atrial fibrillation $(\mathrm{P}<0.001)$. Statistically significant gender interactions in prediction of HF were observed in ECG sign of LVH, inferolateral T-wave inversions, and heart rate. In conclusion, ECG sign of LVH predicts future HF in middleaged women, and T-wave inversions and elevated heart rate are associated with HF hospitalization in men.

Key words: Heart failure, Gender differences, ECG, Left ventricular hypertrophy 


\section{INTRODUCTION}

Heart failure (HF) is one of the leading causes of hospitalization in western societies ${ }^{1}$. In contrast to other heart diseases nearly half of all HF patients ${ }^{2,3}$ and $40-50 \%$ of hospitalized HF patients are women ${ }^{1}$. Despite the improvements in medical treatments, the prognosis of patients with HF has remained poor ${ }^{4}$. Patients hospitalized for HF are experiencing high readmission rates, and though post-discharge survival in women with HF seems to be better than in men ${ }^{2,3,5}$ they have more comorbidities and worse quality of life ${ }^{2,5}$. Even though almost half of the HF patients are women they represent only about $20 \%$ of the study population in randomized trials ${ }^{3}$. Women are underrepresented in most of the data from randomized clinical trials ${ }^{3,5}$ with a couple of exceptions ${ }^{1}$. Also, global registry data on electrocardiographic (ECG) findings in patients hospitalized for HF is limited ${ }^{1}$. We have previously reported the predictive value of ECG markers for all-cause mortality and sudden cardiac death from the Finnish middle-aged population ${ }^{6,7}$. This study examines ECG risk factors for hospitalization in men vs women for HF.

\section{METHODS}

The study population consists of 10,957 subjects between ages 30 and 59 years ( $48 \%$ female, $\mathrm{N}=5,254$ ) from Social Insurance Institution's Coronary Heart Disease Study which is part of large prospective Mobile Clinic Health Survey carried out between 1966 and 1972 in 4 different geographical areas in Finland. Details of the study population have been described previously ${ }^{8}$. After excluding 93 subjects with unreadable electrocardiogram, in the study remained 10,864 subjects with electrocardiogram ( $49 \%$ female, $N=5,215$, mean age $44 \pm 9$ years, Figure 1$)$.

Records for all hospitalizations in Finland have been collected in a nationwide registry maintained by the National Institute for Health and Welfare since 1969 and diagnoses have been validated by Sund et al. ${ }^{9}$. Primary endpoint of the study was hospitalization due to HF until the 31 st 
December 2011. Follow-up period was defined as the time from the initial study visit to the occurrence of hospitalization, death or the end of the follow-up, whichever came first.

Standard resting 12-lead electrocardiograms were recorded at paper speed of $50 \mathrm{~mm} / \mathrm{s}$ at study baseline. The electrocardiograms were analyzed by 9 trained readers for bundle branch blocks, left ventricular hypertrophy (Sokolow-Lyon criteria: R-wave in V5 or V6 $+\mathrm{S}$ wave in V1 $\geq 35 \mathrm{~mm}$, whichever greater) (LVH), QRS duration and QTc interval (corrected for heart rate with Bazett's formula). Minnesota coding was used to assess Q-waves (codes $1.1-1.3$ ), ST segment abnormalities (codes $4.1-4.4$ ) and T-wave items (codes $5.1-5.4$ ). Presence of early repolarization $\geq 0.1 \mathrm{mV}$ with horizontal or descending ST segment and fragmented QRS were assessed as described previously ${ }^{6}$. Early repolarization was classified inferolateral if there were $\geq 2$ slurred or notched J-point elevations $\geq 0.1 \mathrm{mV}$ in inferior (II, III, aVF) or lateral (I, aVL, V4 to V6) leads. ST segment was classified as horizontal or descending if it was under $0.1 \mathrm{mV} 100 \mathrm{~ms}$ after the QRS complex had ended. Fragmented QRS complexes were classified by coronary artery regions as anterior (V1 to V3), inferior or lateral if there were $\geq 2$ fragmented QRS complexes within the region. Similarly, inferolateral T-wave inversions were classified by coronary artery regions as inferior or lateral if T-wave amplitude was < $-0.1 \mathrm{mV}$ in $\geq 2$ contiguous leads in the same region.

Student's t-test was used to compare continuous variables and results are presented as mean \pm standard deviation. Categorial variables were compared between the groups using Pearson ChiSquare test. Interaction between gender and ECG markers was assessed using Cox regression analysis with gender, ECG marker and their interaction term in the same model. If the interaction term was statistically significant, the interaction was further analyzed. Graphical illustration of the interaction was made using the Kaplan-Meier curves. Univariate and multivariate risk ratios were estimated with Cox proportional hazards model. The proportional hazard assumption was verified for each risk marker by plotting Schoenfeld residuals against survival time transformed into natural logarithms. All statistical analyses were performed using Statistical Package for Social Studies 25.0 (SPSS Inc., 
Chicago, IL). All reported P-values are 2-sided and values $<0.05$ are considered as statistically significant.

\section{RESULTS}

Out of the 10,864 subjects ( $49 \%$ female, $N=5,215$ ), a total of 1,743 subjects were hospitalized due to HF during the follow-up time (30 \pm 11 years); $17 \%$ of women $(\mathrm{N}=861)$ and $16 \%$ of men ( $\mathrm{N}=882$; Figure 1). The average time from recording of electrocardiogram to HF hospitalization was $23.7 \pm 11.2$ years, and the average yearly incidence rate for HF hospitalizations were similar between genders: $0.69 \%$ and $0.75 \%$ for women and men, respectively $(\mathrm{P}=0.639)$. Men seemed to have slightly increased risk for HF hospitalization (hazard ratio [HR]: 1.2; 95\% confidence interval [CI]: 1.1-1.3; $\mathrm{P}=0.004)$. Women were older at the time of hospitalization for HF compared to men $(75 \pm 11$ years vs. $70 \pm 11$ years; $\mathrm{P}<0.001)$. The other baseline characteristics of the study population are represented in the Table 1. Gender interaction effects for clinical risk markers of HF hospitalization are represented in Table 2 and unadjusted hazard ratios of clinical risk factors for HF in Table 3.

After hospitalization for HF, 651 women $(76 \%$; $\mathrm{P}<0.001)$ and 721 men $(82 \% ; \mathrm{P}<0.001)$ died during the follow-up, and all-cause mortality was considerably higher than in those without the HF (42\% of women and $61 \%$ of men, respectively; $\mathrm{P}<0.001$ for both). Cardiac death occurred in 249 women and 330 men hospitalized for HF (29\% vs. 37\%; P<0.001 for both) whereas only in $10 \%$ women $(\mathrm{N}=444)$ and $20 \%$ men $(\mathrm{N}=949)$ without hospitalization died for cardiac cause $(\mathrm{P}<0.001$, for both). After HF diagnosis we did not observe gender difference in all-cause mortality (Figure 2) but the rate of cardiac death increased more rapidly among male patients even though in the end of the follow-up time survival in women was only slightly better compared to men (Figure 3). However, significant gender differences in survival could be seen in sudden cardiac death in which the survival among female patient was significantly better compared to men (Figure 4). 
ECG findings in patients with and without HF hospitalization are shown in Table 4. Women with HF hospitalization had increased heart rate compared to men. As expected, women had on average longer QTc duration than men and QTc duration was longer in women with hospitalization for HF than those without hospitalization. However, QTc > $470 \mathrm{~ms}$ in women with hospitalization for HF was less common than QTc > $450 \mathrm{~ms}$ in hospitalized men. In both genders QTc prolongation was more common finding among HF hospitalized patients (Table 4) but did not remain significant in multivariate analysis (Table 5). Even though ECG marker for LVH was more common among men (Table 4) it did not remain statistically significant in multivariable analysis (Table 5). However, ECG sign for LVH was considerably more prevalent in women with hospitalization for HF than those without (Table 4) and remained statistically significant risk factor for HF hospitalization after adjustments with clinical and demographic variables (Table 5). Inferolateral T-wave inversions were more prevalent in men than in women with hospitalization for HF though not statistically significant Also, pathological Q-waves and atrial fibrillation/flutter were more common findings in patients hospitalized for HF, especially in men. (Table 4).

Statistically significant gender interaction was observed in ECG sign of LVH, inferolateral Twave inversions and heart rate (Table 3, Figure 5). ECG evidence of LVH was predictive of HF hospitalization only in women. As opposed to $\mathrm{LVH}$, inferolateral $\mathrm{T}$-wave inversion remained independently predictive of HF hospitalization only in men. (Table 5, Figure 5). Similarly, elevated resting heart rate was associated with outcome only among men. Pathological Q-waves were associated with outcome in both genders but remained independent predictors of HF hospitalization only among men (Table 5). The difference in risk of future hospitalization is represented for each ECG variable by gender and history of ischemic heart disease in Table 6. Prevalence of atrial fibrillation/flutter was very low in this population (Table 4), but it conveyed a significant risk for HF hospitalization in both genders (Table 5). 


\section{DISCUSSION}

The main findings of the study are that there are some gender related differences that predict future hospitalization for HF in middle-aged subjects. Sokolow-Lyon index of LVH in the ECG predicted HF hospitalization only in women and T-wave inversions only in men. Pathological Qwaves and elevated heart rate increased the risk for HF hospitalization only in men. To our knowledge, there are only few large-scale studies assessing the role of standard 12-lead electrocardiography in predicting the occurrence of HF. Furthermore, most of the studies have predominantly included men in their data collection and analysis ${ }^{3,5}$.

ECG sign of LVH, assessed by Sokolow-Lyon index, was the most important risk factor of HF in women but not in men, even though it was more commonly found in men. The prevalence difference between genders may be explained with the higher average BMI of women as we know from the earlier literature that the sensitivity of Sokolow-Lyon criteria is low especially among obese women ${ }^{10}$. LVH has been previously associated with higher incidence and earlier development of HF in elderly population ${ }^{11}$. In addition, the LIFE study ${ }^{12}$ found that regression in LVH defined by criteria of Cornell decreased the risk of HF and death. LVH has been most commonly associated with undiagnosed and/or poorly controlled hypertension ${ }^{13}$, and when detected by echocardiographic is more prevalent finding in women than in men among hypertensive patients ${ }^{14}$ suggesting that adequate control of blood pressure may be crucial in prevention of HF especially in women.

After adjustments T-inversions and Q-waves were associated with HF hospitalization only in men, although the prevalence of inferolateral T-wave inversions was quite low in both genders. These kind of ECG abnormalities are quite common among patient with advanced HF and prior myocardial infarction or cardiomyopathy, and as the coronary artery disease is more prevalent cause of HF among men $2,3,15,16$ it may explain the gender differences. However, when analysing the risk for HF hospitalization taking into account the history of ischemic heart disease, the risk for HF hospitalization did not differ considerably among male subjects with and without ischemic heart 
disease. In the present study, atrial fibrillation or flutter in the analysed electrocardiogram was associated with increased risk for HF hospitalization among both genders. However, the prevalence of atrial fibrillation in this study was extremely low. Previously, many studies have shown the adverse effect of atrial fibrillation among HF patients ${ }^{17}$, but the evidence to suggest that atrial fibrillation would ultimately cause HF are lacking. After all, almost all the risk factors for HF are interchangeable with atrial fibrillation risk ${ }^{17}$. In addition, among men the increased heart rate was among statistically significant risk factors for HF hospitalization which is in line with previous studies ${ }^{18}$.

The prevalence of hospitalization for HF during the follow-up time was similar in both genders, as well as the average yearly incidence rate for HF hospitalizations. Higher hospitalization and readmission rates for women have been previously reported in some studies ${ }^{19}$ while other studies ${ }^{31}$ have shown higher rates among men. Male gender increased risk for hospitalization which is consistent with some of the previous studies ${ }^{22}$ but not with all ${ }^{23,24}$. Women hospitalized for HF had a lower prevalence of cardiac death or all-cause mortality in comparison to men. Taking account that main causes of death of HF patients are sudden cardiac death and progressive pump failure ${ }^{25}$, one explanation for better survival of women could be the higher prevalence of HF with preserved ejection fraction in women ${ }^{2}$ and the different etiology behind HF in women and men ${ }^{2,3}$.

However, among hospitalized women the rate of cardiac death during the first 2 decades of the follow-up time was lower compared to men, but the gender difference narrowed considerably towards the end of the follow-up time. We did not notice gender differences in survival of all-cause mortality. Women had considerably better prognosis for sudden cardiac death compared to men. Previous data considering the prognosis of women with HF hospitalization is controversial with most of the studies supporting the greater prognostic value of HF in women ${ }^{2,3}$ while some suggesting the opposite ${ }^{28}$ and some did not find difference in in-hospital and post-discharge outcomes between the genders ${ }^{29}$.

One possible limitation in this study is the fact that medication and other treatments for HF have changed dramatically during the long follow-up period and all results might not be completely 
transferable to current era. It is also possible that the health behaviour has changed remarkably during the long follow-up period. In addition, we did not have echocardiographic data in this population and thus cannot evaluate proportion of HF with or without systolic or diastolic left ventricular dysfunction. As well, we were not able to use a criteria of a total 12-lead QRS voltage as ECG sign of LVH which has been previously reported in some studies as superior to other ECG criteria for $\mathrm{LVH}^{30}$, and also data of strain changes lacked. Nevertheless, this is to our knowledge the largest general population cohort with extensive follow-up and validated outcome data.

In conclusion, we studied clinical and ECG risk markers for hospitalization due to HF in middle aged general population in Finland. Among patients who had experienced hospitalization for HF, ECG sign of LVH was a significant risk factor for future HF hospitalization in women but not in men, and inferolateral T-wave inversion was a risk factor in men but not in women. Pathological Q-waves and elevated heart rate increased risk for hospitalization only in men. Overall, the present data show that if LVH is observed in a standard 12-lead electrocardiogram in a middle-aged woman, emphasis should be put on adequate treatment of hypertension or diagnosing other possible causes of LVH to prevent future HF.

\section{ACKNOWLEDGEMENTS}

This study has been carried out in collaboration with National Institute for Health and Welfare and supported in part by Sigrid Juselius Foundation, Helsinki, Finland (HH, JT, AA), Finnish Medical Foundation, Helsinki, Finland (AA, AH), Instrumentarium Science Foundation, Helsinki, Finland (JT), Juho Vainio Foundation (AH), Helsinki, Finland, Maud Kuistila Memorial Foundation, Helsinki, Finland (AH), Finnish Foundation for cardiovascular Research, Helsinki, Finland (AH), Paulo Foundation, Espoo, Finland (AH), Aarne Koskelo Foundation, Helsinki, Finland (AH), Päivikki and Sakari Sohlberg Foundation, Helsinki, Finland (AH). 
1. Ambrosy AP, Fonarow GC, Butler J, Chioncel O, Greene SJ, Vaduganathan M, Nodari S, Lam CSP, Sato N, Shah AN, Gheorghiade M. The Global Health and Economic Burden of Hospitalizations for Heart Failure. J Am Coll Cardiol 2014;63:1123-1133. Available at: https://linkinghub.elsevier.com/retrieve/pii/S0735109714002915. Accessed November 12, 2018. 2. Taylor AL. Heart Failure in Women. Curr Heart Fail Rep 2015;12:187-195. Available at: http://www.ncbi.nlm.nih.gov/pubmed/25633565. Accessed November 12, 2018.

3. Hsich EM, Piña IL. Heart Failure in Women. J Am Coll Cardiol 2009;54:491-498. Available at: http://linkinghub.elsevier.com/retrieve/pii/S0735109709012066. Accessed November 12, 2018.

4. Roger VL, Weston SA, Redfield MM, Hellermann-Homan JP, Killian J, Yawn BP, Jacobsen SJ. Trends in heart failure incidence and survival in a community-based population. JAMA 2004;292:344-50. Available at:

http://jama.jamanetwork.com/article.aspx?doi=10.1001/jama.292.3.344. Accessed November 12, 2018.

5. Dunlay SM, Roger VL. Gender Differences in the Pathophysiology, Clinical Presentation, and Outcomes of Ischemic Heart Failure. Curr Heart Fail Rep 2012;9:267-276. Available at: http://link.springer.com/10.1007/s11897-012-0107-7. Accessed November 12, 2018.

6. Tikkanen JT, Anttonen O, Junttila MJ, Aro AL, Kerola T, Rissanen HA, Reunanen A, Huikuri H V. Long-term outcome associated with early repolarization on electrocardiography. $N$ Engl J Med 2009;361:2529-37. Available at: http://www.nejm.org/doi/abs/10.1056/NEJMoa0907589. Accessed November 12, 2018.

7. Aro AL, Anttonen O, Tikkanen JT, Junttila MJ, Kerola T, Rissanen HA, Reunanen A, Huikuri H V. Prevalence and Prognostic Significance of T-Wave Inversions in Right Precordial Leads of a 12Lead Electrocardiogram in the Middle-Aged Subjects. Circulation 2012;125:2572-2577. Available at: http://www.ncbi.nlm.nih.gov/pubmed/22576982. Accessed October 15, 2019.

8. Reunanen A, Aromaa A, Pyörälä K, Punsar S, Maatela J, Knekt P. The Social Insurance 
Institution's coronary heart disease study. Baseline data and 5-year mortality experience. Acta Med Scand Suppl 1983;673:1-120. Available at: http://www.ncbi.nlm.nih.gov/pubmed/6578675. Accessed November 12, 2018.

9. Sund R. Quality of the Finnish Hospital Discharge Register: a systematic review. Scand J Public Health 2012;40:505-15. Available at: http://journals.sagepub.com/doi/10.1177/1403494812456637. Accessed November 28, 2018.

10. Snelder SM, Poll SWE van de, Groot - de Laat LE de, Kardys I, Zijlstra F, Dalen BM van. Optimized electrocardiographic criteria for the detection of left ventricular hypertrophy in obesity patients. Clin Cardiol 2020.

11. Aronow WS, Ahn C. Association of electrocardiographic left ventricular hypertrophy with the incidence of new congestive heart failure. J Am Geriatr Soc 1998;46:1280-1. Available at: http://www.ncbi.nlm.nih.gov/pubmed/9777912. Accessed November 17, 2018.

12. Larstorp ACK, Okin PM, Devereux RB, Olsen MH, Ibsen H, Dahlöf B, Kjeldsen SE, Wachtell K. Regression of ECG-LVH is associated with lower risk of new-onset heart failure and mortality in patients with isolated systolic hypertension; The LIFE study. Am J Hypertens 2012;25:1101-9. Available at: https://academic.oup.com/ajh/article-lookup/doi/10.1038/ajh.2012.86. Accessed November 17, 2018.

13. Garg S, Drazner MH. Refining the classification of left ventricular hypertrophy to provide new insights into the progression from hypertension to heart failure. Curr Opin Cardiol 2016;31:387393. Available at: http://www.ncbi.nlm.nih.gov/pubmed/27168169. Accessed November 20, 2018. 14. Gerdts E, Izzo R, Mancusi C, Losi MA, Manzi MV, Canciello G, Luca N De, Trimarco B, Simone G de. Left ventricular hypertrophy offsets the sex difference in cardiovascular risk (the Campania Salute Network). Int J Cardiol 2018;258:257-261. Available at: https://linkinghub.elsevier.com/retrieve/pii/S016752731736165X. Accessed November 28, 2018. 15. O’Meara E, Clayton T, McEntegart MB, McMurray JJ V, Piña IL, Granger CB, Ostergren J, 
Michelson EL, Solomon SD, Pocock S, Yusuf S, Swedberg K, Pfeffer MA, CHARM Investigators. Sex differences in clinical characteristics and prognosis in a broad spectrum of patients with heart failure: results of the Candesartan in Heart failure: Assessment of Reduction in Mortality and morbidity (CHARM) program. Circulation 2007;115:3111-20. Available at: https://www.ahajournals.org/doi/10.1161/CIRCULATIONAHA.106.673442. Accessed November $12,2018$.

16. Ghali JK, Krause-Steinrauf HJ, Adams KF, Khan SS, Rosenberg YD, Yancy CW, Young JB, Goldman S, Peberdy MA, Lindenfeld J. Gender differences in advanced heart failure: insights from the BEST study. J Am Coll Cardiol 2003;42:2128-34. Available at: http://www.ncbi.nlm.nih.gov/pubmed/14680739. Accessed November 12, 2018. 17. Wang TJ, Larson MG, Levy D, Vasan RS, Leip EP, Wolf PA, D’Agostino RB, Murabito JM, Kannel WB, Benjamin EJ. Temporal relations of atrial fibrillation and congestive heart failure and their joint influence on mortality: the Framingham Heart Study. Circulation 2003;107:2920-5. Available at: https://www.ahajournals.org/doi/10.1161/01.CIR.0000072767.89944.6E. Accessed November 20, 2018.

18. Giamouzis G, Kalogeropoulos A, Georgiopoulou V, Laskar S, Smith AL, Dunbar S, Triposkiadis F, Butler J. Hospitalization epidemic in patients with heart failure: risk factors, risk prediction, knowledge gaps, and future directions. J Card Fail 2011;17:54-75. Available at: http://linkinghub.elsevier.com/retrieve/pii/S1071916410010894. Accessed November 12, 2018. 19. Frazier CG, Alexander KP, Newby LK, Anderson S, Iverson E, Packer M, Cohn J, Goldstein S, Douglas PS. Associations of gender and etiology with outcomes in heart failure with systolic dysfunction: a pooled analysis of 5 randomized control trials. J Am Coll Cardiol 2007;49:1450-8. Available at: https://linkinghub.elsevier.com/retrieve/pii/S0735109707002434. Accessed September $12,2019$.

20. Dunlay SM, Redfield MM, Weston SA, Therneau TM, Hall Long K, Shah ND, Roger VL. 
Hospitalizations after heart failure diagnosis a community perspective. J Am Coll Cardiol 2009;54:1695-702. Available at: http://linkinghub.elsevier.com/retrieve/pii/S0735109709029234. Accessed November 12, 2018.

21. Harjai KJ, Thompson HW, Turgut T, Shah M. Simple clinical variables are markers of the propensity for readmission in patients hospitalized with heart failure. Am J Cardiol 2001;87:234-7, A9. Available at: http://www.ncbi.nlm.nih.gov/pubmed/11152851. Accessed November 12, 2018. 22. Savarese G, D’Amario D. Sex Differences in Heart Failure. In: ; 2018:529-544. Available at: http://link.springer.com/10.1007/978-3-319-77932-4_32. Accessed November 12, 2018.

23. Deswal A, Bozkurt B. Comparison of morbidity in women versus men with heart failure and preserved ejection fraction. Am J Cardiol 2006;97:1228-31. Available at: http://linkinghub.elsevier.com/retrieve/pii/S0002914906000464. Accessed November 12, 2018. 24. Galvao M, Kalman J, DeMarco T, Fonarow GC, Galvin C, Ghali JK, Moskowitz RM. Gender differences in in-hospital management and outcomes in patients with decompensated heart failure: analysis from the Acute Decompensated Heart Failure National Registry (ADHERE). J Card Fail 2006;12:100-7. Available at: http://linkinghub.elsevier.com/retrieve/pii/S1071916405013114. Accessed November 12, 2018.

25. SOLVD Investigators, Yusuf S, Pitt B, Davis CE, Hood WB, Cohn JN. Effect of enalapril on survival in patients with reduced left ventricular ejection fractions and congestive heart failure. $N$ Engl J Med 1991;325:293-302. Available at: http://www.nejm.org/doi/10.1056/NEJM199108013250501. Accessed September 12, 2019. 26. Lam CSP, Voors AA, Boer RA de, Solomon SD, Veldhuisen DJ van. Heart failure with preserved ejection fraction: from mechanisms to therapies. Eur Heart J 2018;39:2780-2792. Available at: http://www.ncbi.nlm.nih.gov/pubmed/29905796. Accessed November 17, 2018. 27. Corrado D, Pelliccia A, Heidbuchel H, Sharma S, Link M, Basso C, Biffi A, Buja G, Delise P, Gussac I, Anastasakis A, Borjesson M, Bjørnstad HH, Carrè F, Deligiannis A, Dugmore D, Fagard 
R, Hoogsteen J, Mellwig KP, Panhuyzen-Goedkoop N, Solberg E, Vanhees L, Drezner J, Estes NAM, Iliceto S, Maron BJ, Peidro R, Schwartz PJ, Stein R, Thiene G, Zeppilli P, McKenna WJ, Section of Sports Cardiology, European Association of Cardiovascular Prevention and Rehabilitation. Recommendations for interpretation of 12-lead electrocardiogram in the athlete. Eur Heart J 2010;31:243-59. Available at: https://academic.oup.com/eurheartj/articlelookup/doi/10.1093/eurheartj/ehp473. Accessed November 20, 2018.

28. Tribouilloy C, Rusinaru D, Mahjoub H, Soulière V, Lévy F, Peltier M, Slama M, Massy Z. Prognosis of heart failure with preserved ejection fraction: a 5 year prospective population-based study. Eur Heart J 2008;29:339-47. Available at: https://academic.oup.com/eurheartj/articlelookup/doi/10.1093/eurheartj/ehm554. Accessed November 12, 2018.

29. Meyer S, Teerlink JR, Metra M, Ponikowski P, Cotter G, Davison BA, Felker GM, Filippatos G, Greenberg BH, Hua TA, Severin T, Qian M, Voors AA. Sex differences in early dyspnea relief between men and women hospitalized for acute heart failure: insights from the RELAX-AHF study. Clin Res Cardiol 2017;106:280-292. Available at: http://link.springer.com/10.1007/s00392-0161051-4. Accessed November 12, 2018.

30. Roberts WC, Filardo G, Ko JM, Siegel RJ, Dollar AL, Ross EM, Shirani J. Comparison of total 12-lead QRS voltage in a variety of cardiac conditions and its usefulness in predicting increased cardiac mass. Am J Cardiol 2013;112:904-9. Available at: http://www.ncbi.nlm.nih.gov/pubmed/23768457. Accessed April 23, 2020. 
FIGURE LEGENDS

Figure 1. Flow chart of the study.

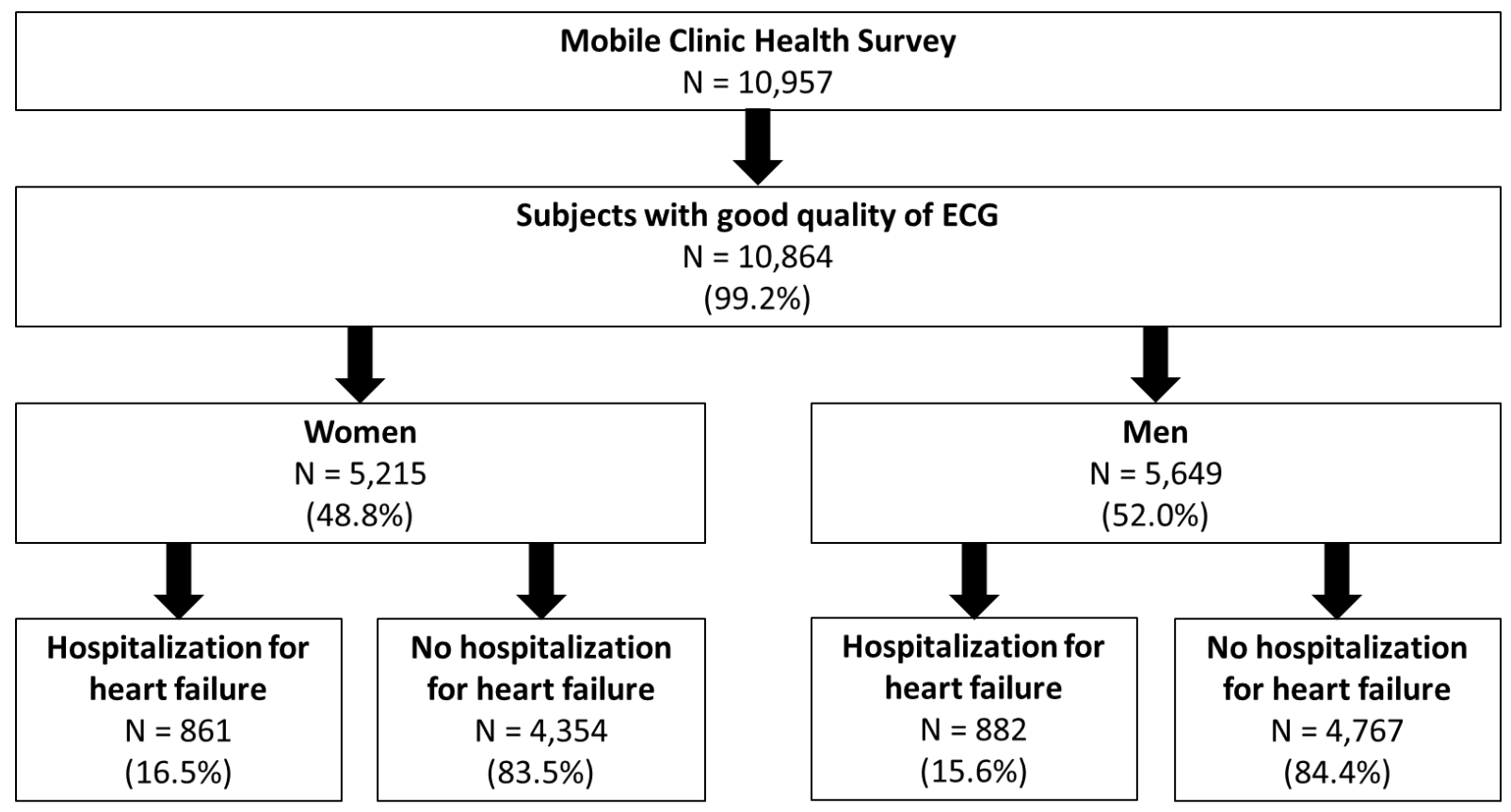

Figure 2. Kaplan-Meier curves of all-cause mortality for men and women after the diagnosis of HF.

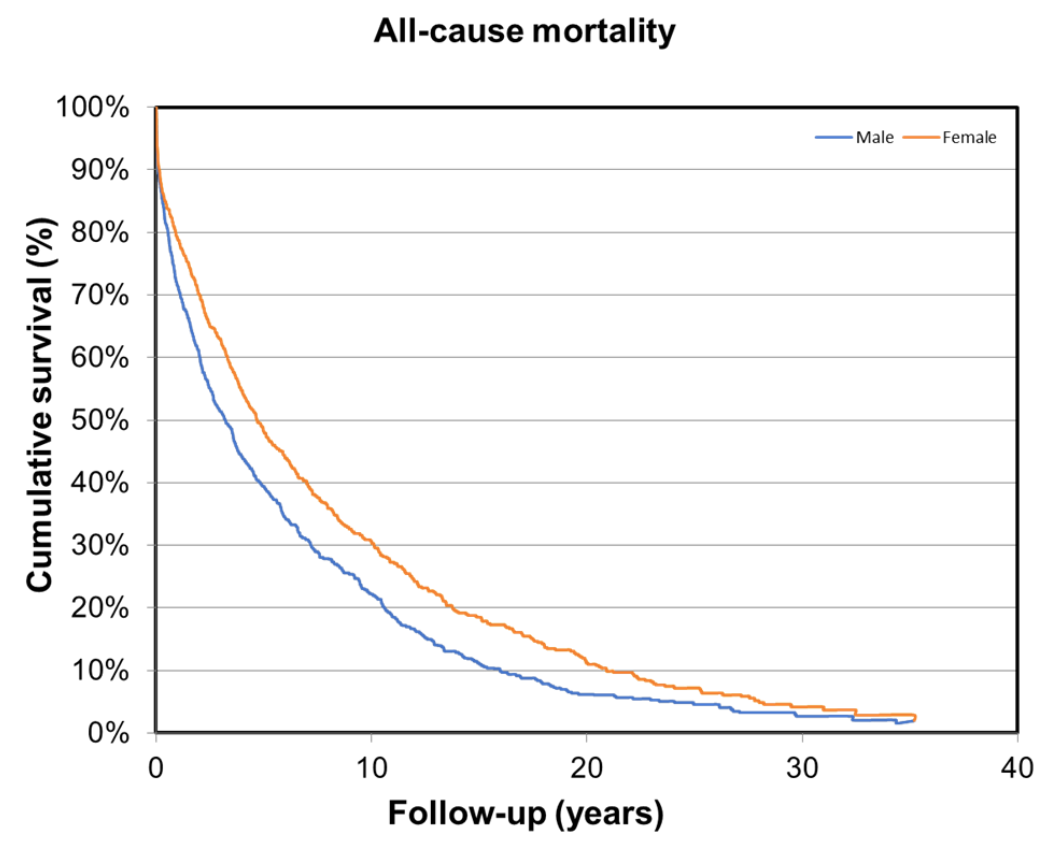

Log-rank test: Chi-square 21.6, $\mathrm{P}<0.001$ 
Figure 3. Kaplan-Meier curves of cardiac mortality for men and women after the diagnosis of HF.

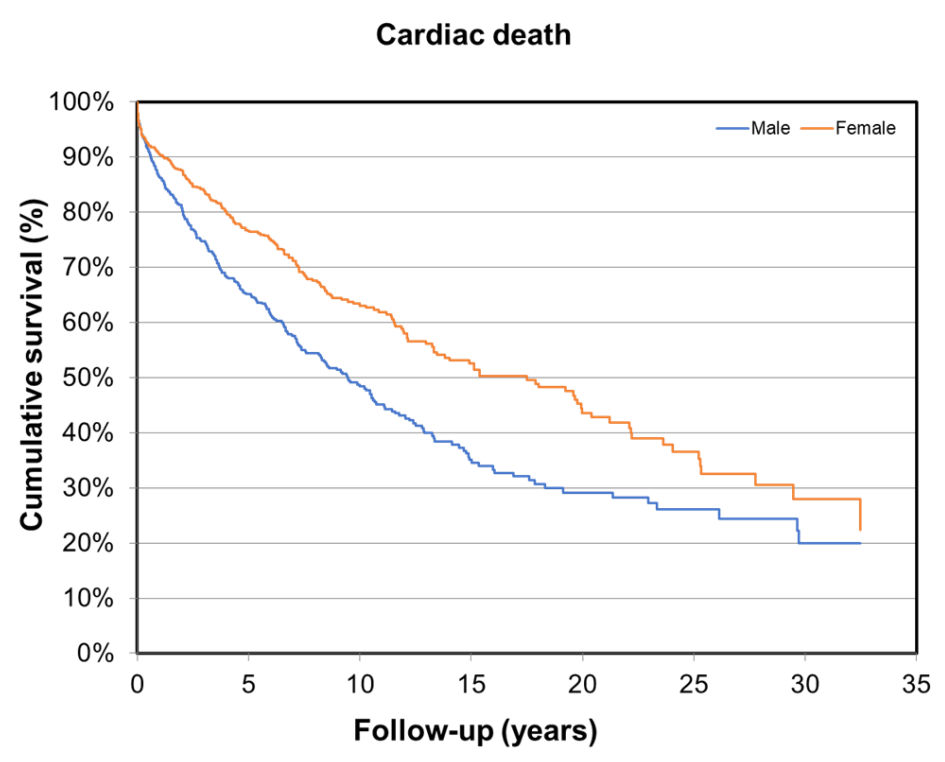

Log-rank test: Chi-square 26.7, $\mathrm{P}<0.001$

Figure 4. Kaplan-Meier curves of sudden cardiac death for men and women after the diagnosis of $H F$.

Sudden cardiac death

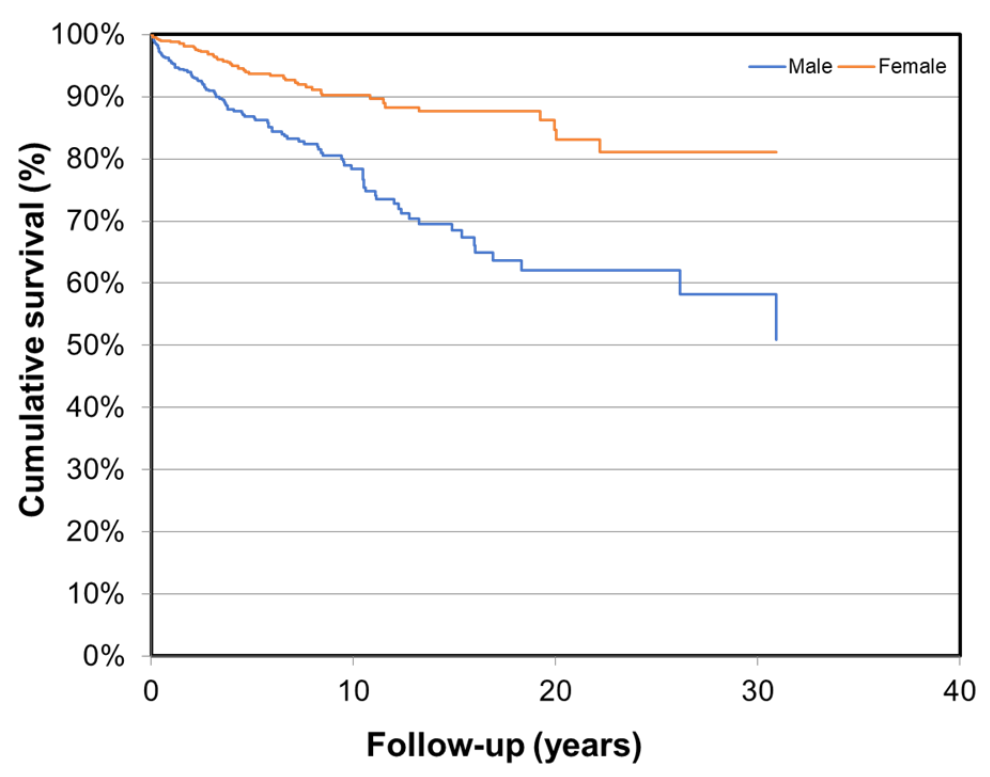

Log-rank test: Chi-square 36.7, $\mathrm{P}<0.001$ 
Figure 5. Kaplan-Meier curves for men and women with and without ECG-based LVH and T-wave inversion.

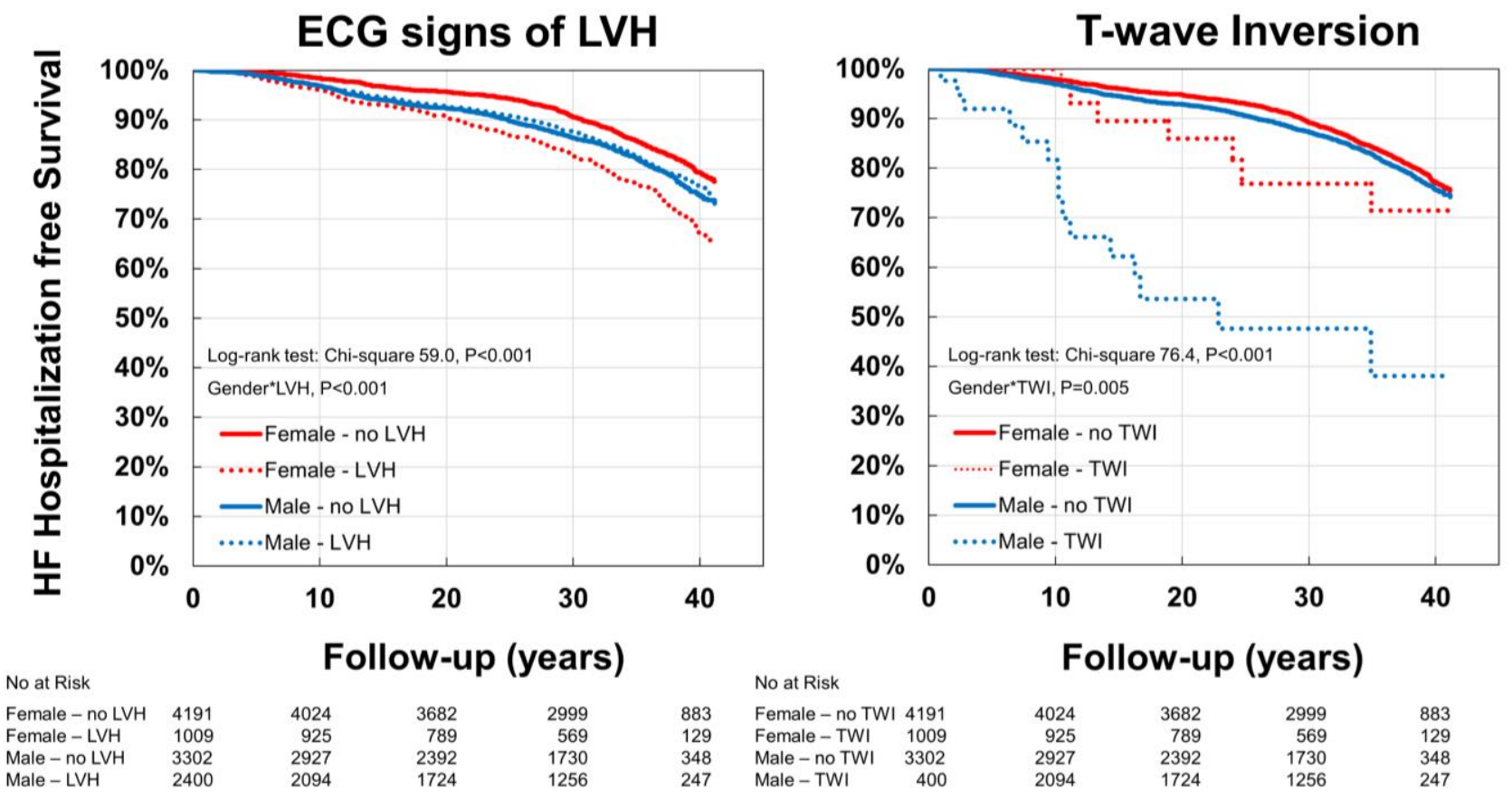


Table 1. Baseline characteristics of HF hospitalized subjects and subjects who were not hospitalized due to HF among men and women.

\begin{tabular}{|c|c|c|c|c|c|c|}
\hline \multirow[b]{3}{*}{ Variable } & \multicolumn{2}{|c|}{$\begin{array}{l}\text { Women } \\
(\mathrm{N}=5,215)\end{array}$} & \multicolumn{4}{|c|}{$\begin{array}{c}\text { Men } \\
(\mathrm{N}=5,649)\end{array}$} \\
\hline & Control & HF hospitalization & & Control & HF hospitalization & \\
\hline & $\mathrm{N}=4,354(83 \%)$ & $\mathrm{N}=861(17 \%)$ & & $\mathrm{N}=4,767(84 \%)$ & $\mathrm{N}=882(16 \%)$ & \\
\hline & Mean \pm SD & Mean \pm SD & P-value & Mean \pm SD & Mean \pm SD & P-value \\
\hline Age (years) & $43 \pm 8$ & $50 \pm 7$ & $<0.001$ & $43 \pm 8$ & $47 \pm 8$ & $<0.001$ \\
\hline BMI $\left(\mathrm{kg} / \mathrm{m}^{2}\right)$ & $26 \pm 4$ & $28 \pm 5$ & $<0.001$ & $25 \pm 3$ & $27 \pm 4$ & $<0.001$ \\
\hline $\begin{array}{l}\text { Systolic blood pressure } \\
(\mathrm{mmHg})\end{array}$ & $137 \pm 23$ & $146 \pm 27$ & $<0.001$ & $138 \pm 19$ & $141 \pm 22$ & $<0.001$ \\
\hline $\begin{array}{l}\text { Diastolic blood pressure } \\
(\mathrm{mmHg})\end{array}$ & $83 \pm 12$ & $87 \pm 13$ & $<0.001$ & $81 \pm 12$ & $84 \pm 14$ & $<0.001$ \\
\hline Follow-up time (years) & $33 \pm 9$ & $25 \pm 11$ & $<0.001$ & $29 \pm 12$ & $22 \pm 11$ & $<0.001$ \\
\hline
\end{tabular}


Table 2. Risk of HF hospitalization and gender interactions.

\begin{tabular}{|c|c|c|c|}
\hline \multirow[t]{2}{*}{ Variable } & \multicolumn{3}{|c|}{ Women vs. Men } \\
\hline & Risk & $95 \% \mathrm{CI}$ & P-value \\
\hline Age (years) & 1.0 & $1.0-1.0$ & 0.012 \\
\hline $\mathrm{BMI}\left(\mathrm{kg} / \mathrm{m}^{2}\right)$ & 1.0 & $1.0-1.0$ & 0.116 \\
\hline $\begin{array}{l}\text { Systolic blood pressure } \\
(\mathrm{mmHg})\end{array}$ & 1.0 & $1.0-1.0$ & 0.010 \\
\hline $\begin{array}{l}\text { Diastolic blood pressure } \\
(\mathrm{mmHg})\end{array}$ & 1.0 & $1.0-1.0$ & 0.009 \\
\hline Heart rate $(1 / \mathrm{min})$ & 1.0 & $1.0-1.0$ & 0.017 \\
\hline Previous cardiac disease & 1.3 & $0.8-1.3$ & 0.792 \\
\hline Medication for hypertension & 0.5 & $0.3-0.7$ & $<0.001$ \\
\hline Smoker & 0.7 & $0.5-0.8$ & 0.003 \\
\hline $\mathrm{QRS} \geq 110 \mathrm{~ms}$ & 0.9 & $0.4-2.0$ & 0.758 \\
\hline $\mathrm{QTc} \geq 470 / 450 \mathrm{~ms}^{*}$ & 1.0 & $0.6-1.7$ & 0.966 \\
\hline
\end{tabular}




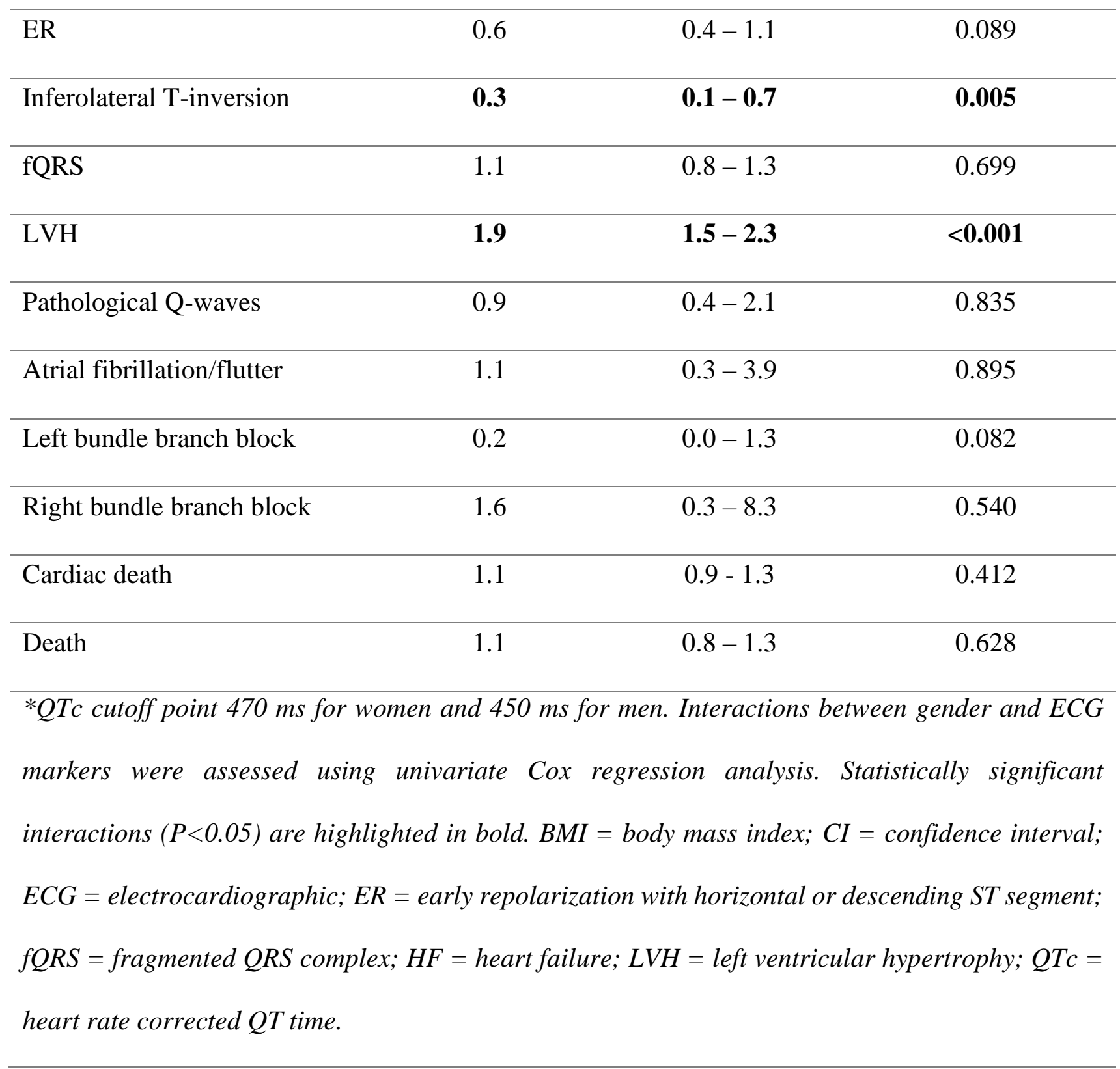


Table 3. Unadjusted hazard ratios of clinical risk factors resulting to hospitalization for HF during the follow-up.

\begin{tabular}{|c|c|c|c|c|c|c|}
\hline \multirow[b]{3}{*}{ Variable } & \multicolumn{3}{|c|}{ Women } & \multicolumn{3}{|c|}{ Men } \\
\hline & \multicolumn{3}{|c|}{$(\mathrm{N}=5,215)$} & \multicolumn{3}{|c|}{$(\mathrm{N}=5,649)$} \\
\hline & HR & $95 \% \mathrm{CI}$ & $\mathrm{P}$-value & HR & $95 \% \mathrm{CI}$ & P-value \\
\hline Age (years) & 1.2 & $1.1-1.2$ & $<0.001$ & 1.1 & $1.1-1.1$ & $<0.001$ \\
\hline $\mathrm{BMI}\left(\mathrm{kg} / \mathrm{m}^{2}\right)$ & 1.1 & $1.1-1.1$ & $<0.001$ & 1.1 & $1.1-1.1$ & $<0.001$ \\
\hline Systolic blood pressure (mmHg) & 1.0 & $1.0-1.0$ & $<0.001$ & 1.0 & $1.0-1.0$ & $<0.001$ \\
\hline $\begin{array}{l}\text { Diastolic blood pressure } \\
(\mathrm{mmHg})\end{array}$ & 1.0 & $1.0-1.0$ & $<0.001$ & $\mathbf{1 . 0}$ & $1.0-1.0$ & $<0.001$ \\
\hline Smoker & 1.0 & $0.8-1.2$ & 0.888 & 1.4 & $1.2-1.6$ & $<0.001$ \\
\hline Medication for hypertension & 3.2 & $2.6-4.0$ & $<0.001$ & 6.3 & $4.7-8.4$ & $<0.001$ \\
\hline Previous cardiac disease & 3.8 & $3.1-4.6$ & $<0.001$ & 3.7 & $3.1-4.5$ & $<0.001$ \\
\hline
\end{tabular}


Subject is considered as a smoker if she/he smokes cigarettes, cigars or pipe daily. Hazard ratios were analyzed using unadjusted Cox Regression analysis. Significant differences $(P<0.05)$ between subjects with and without hospitalization for HF highlighted in bold. BMI = body mass index; $C I=$ confidence interval; $H F=$ heart failure; HR = hazard ratio.

Table 4. Comparison of ECG variables between HF hospitalized subjects and subjects who were not hospitalized due to HF.

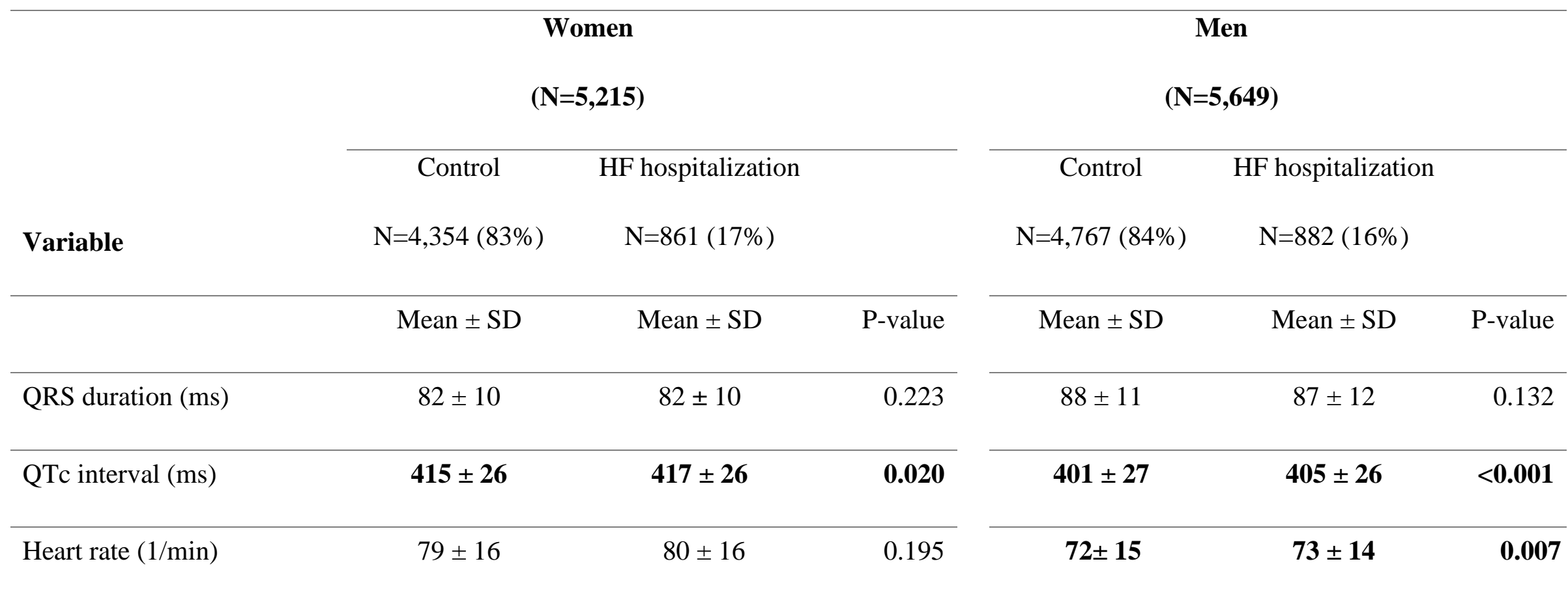




\begin{tabular}{|c|c|c|c|c|c|c|}
\hline & $\mathrm{N}(\%)$ & $\mathrm{N}(\%)$ & P-value & $\mathrm{N}(\%)$ & $\mathrm{N}(\%)$ & P-value \\
\hline $\mathrm{QRS} \geq 110 \mathrm{~ms}$ & $35(0.8 \%)$ & $7(0.8 \%)$ & 0.954 & $224(5 \%)$ & $50(6 \%)$ & 0.194 \\
\hline $\mathrm{QTc} \geq 470 / 450 \mathrm{~ms}^{*}$ & $83(2 \%)$ & $27(3 \%)$ & 0.023 & $187(4 \%)$ & $47(5 \%)$ & 0.044 \\
\hline ER & $157(4 \%)$ & $19(2 \%)$ & 0.039 & $189(4 \%)$ & $36(4 \%)$ & 0.832 \\
\hline Inferolateral T-inversion & $26(0.6 \%)$ & $7(0.8 \%)$ & 0.368 & $30(0.6 \%)$ & $15(2 \%)$ & 0.001 \\
\hline fQRS & $644(15 \%)$ & $145(17 \%)$ & 0.140 & $997(21 \%)$ & $203(24 \%)$ & 0.095 \\
\hline Anterior & $135(3 \%)$ & $27(4 \%)$ & 0.376 & $142(4 \%)$ & $32(5 \%)$ & 0.214 \\
\hline Inferior & $553(13 \%)$ & $120(15 \%)$ & 0.152 & $885(19 \%)$ & $179(21 \%)$ & 0.129 \\
\hline Lateral & $30(0.7 \%)$ & $7(1 \%)$ & 0.339 & $45(1 \%)$ & $8(1 \%)$ & 0.978 \\
\hline LVH & $788(18 \%)$ & $223(26 \%)$ & $<0.001$ & $2,046(42 \%)$ & $354(40 \%)$ & 0.203 \\
\hline Pathological Q-waves & $57(1 \%)$ & $77(3 \%)$ & 0.005 & $104(2 \%)$ & $39(4 \%)$ & $<0.001$ \\
\hline Atrial fibrillation/flutter & $4(0.1 \%)$ & $5(0.6 \%)$ & $<0.001$ & $6(0.1 \%)$ & $8(0.9 \%)$ & $<0.001$ \\
\hline Left bundle branch block & $13(0.3 \%)$ & $1(0.1 \%)$ & 0.387 & $15(0.3 \%)$ & $5(0.6 \%)$ & 0.241 \\
\hline
\end{tabular}




\begin{tabular}{llllll}
\hline Right bundle branch block & $9(0.2 \%)$ & $3(0.3 \%)$ & 0.531 & $28(0.6 \%)$ & $3(0.3 \%)$
\end{tabular}

*QTc cutoff point $470 \mathrm{~ms}$ for women and $450 \mathrm{~ms}$ for men. Statistical analyses are made without adjustments using Student's $t$-test for continuous variables and Pearson Chi-Square test for categorial variables. Significant differences $(P<0.05)$ between subjects with and without hospitalization for HF highlighted in bold. ECG = electrocardiographic; ER = early repolarization with horizontal or descending ST segment; $f Q R S=$ fragmented $Q R S$ complex $; H F=$ heart failure LVH = left ventricular hypertrophy; $Q T c=$ heart rate corrected $Q T c$ time $; S D=$ standard deviation.

Table 5. Hazard ratios of ECG variables as predictors of HF hospitalization among men and women.

\begin{tabular}{|c|c|c|c|c|c|c|c|c|c|c|c|c|}
\hline \multirow[b]{3}{*}{ Variable } & \multicolumn{6}{|c|}{$\begin{array}{c}\text { Women } \\
(\mathrm{N}=5,215)\end{array}$} & \multicolumn{6}{|c|}{$\begin{array}{c}\text { Men } \\
(\mathrm{N}=\mathbf{5 , 6 4 9 )}\end{array}$} \\
\hline & \multicolumn{3}{|c|}{ Unadjusted } & \multicolumn{3}{|c|}{ Adjusted } & \multicolumn{3}{|c|}{ Unadjusted } & \multicolumn{3}{|c|}{ Adjusted } \\
\hline & HR & $95 \% \mathrm{CI}$ & P-value & HR & $95 \% \mathrm{CI}$ & P-value & HR & $95 \% \mathrm{CI}$ & P-value & HR & $95 \% \mathrm{CI}$ & P-value \\
\hline Heart rate $(1 / \mathrm{min})$ & 1.0 & $1.0-1.1$ & 0.701 & 1.0 & $1.0-1.1$ & 0.686 & 1.1 & $1.1-1.1$ & $<0.001$ & 1.1 & $1.0-1.1$ & 0.008 \\
\hline $\mathrm{QRS} \geq 110 \mathrm{~ms}$ & 01.0 & $0.5-2.1$ & 0.988 & 0.7 & $0.3-1.6$ & 0.402 & 1.1 & $0.9-1.5$ & 0.371 & 1.3 & $1.0-1.7$ & 0.114 \\
\hline $\mathrm{QTc} \geq 470 / 450 \mathrm{~ms}^{*}$ & 1.9 & $1.3-2.8$ & 0.001 & 1.2 & $0.8-1.8$ & 0.275 & 1.8 & $1.3-2.4$ & $<0.001$ & 1.9 & $1.7-2.2$ & 0.095 \\
\hline ER & 0.7 & $0.5-1.2$ & 0.187 & 0.6 & $0.4-0.9$ & 0.025 & 1.2 & $0.9-1.7$ & 0.274 & 1.2 & $0.8-2.2$ & 0.397 \\
\hline
\end{tabular}




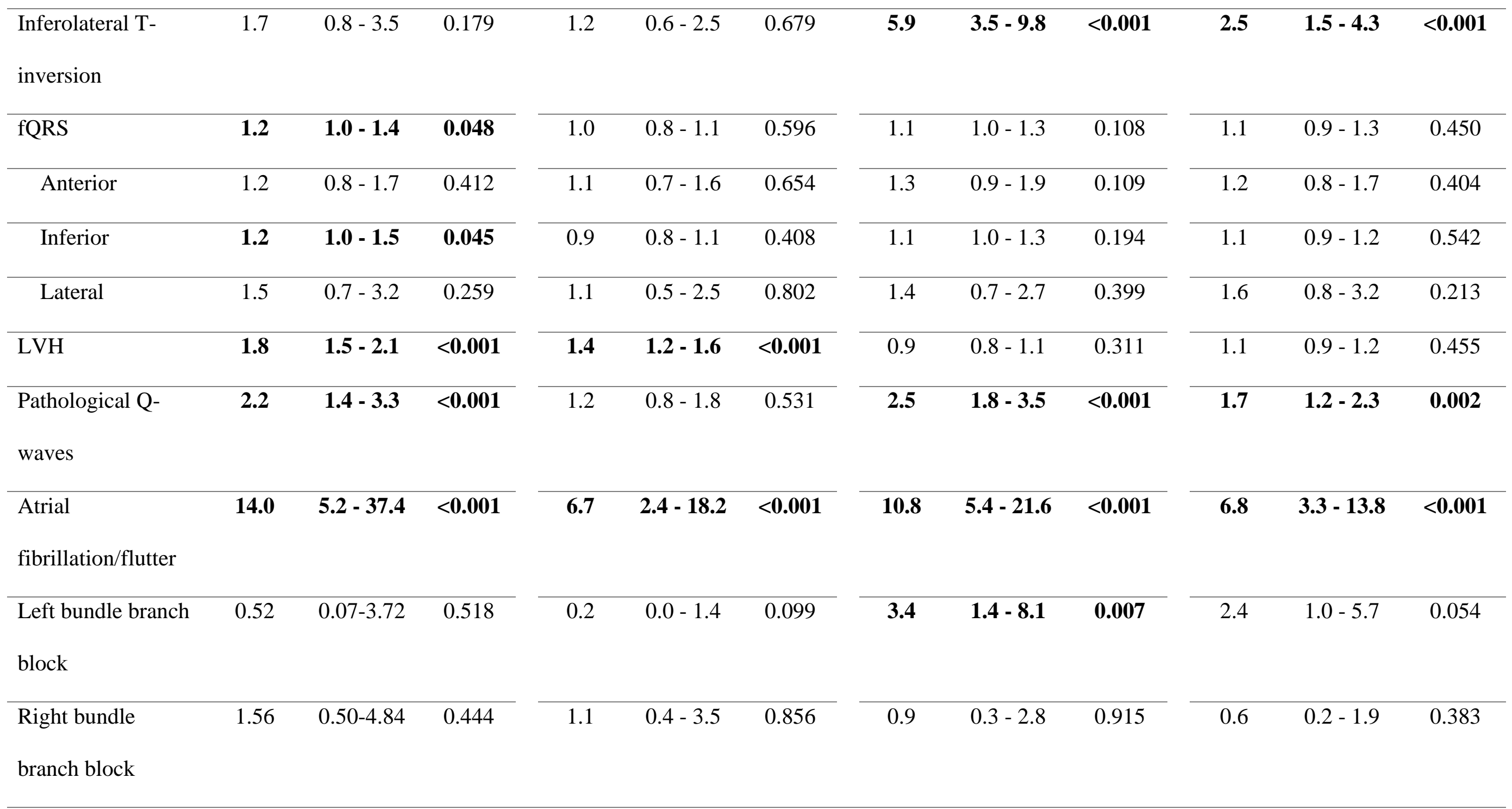


*QTc cutoff point 470ms for women and 450ms for men. Statistical analysis was performed using Cox regression analysis. Adjustments for age, BMI, smoking, diastolic blood pressure, prior cardiac disease and medication for arterial hypertension. Significant differences $(P<0.05)$ between subjects with and without hospitalization for HF highlighted in bold. BMI = body mass index; $C I=$ confidence interval; ECG = electrocardiographic; ER $=$ early repolarization with horizontal or descending ST segment; fQRS = fragmented $Q R S$ complex; HF = heart failure; HR = hazard ratio; LVH = left ventricular hypertrophy; $Q T c=$ corrected QT time.

Table 6. Hazard ratios of ECG variables as predictors of HF hospitalization by the history of ischemic heart disease.

\begin{tabular}{|c|c|c|c|c|c|c|c|c|c|c|c|c|}
\hline \multirow{4}{*}{ Variable } & \multicolumn{6}{|c|}{$\begin{array}{c}\text { Women } \\
(\mathrm{N}=5,201)\end{array}$} & \multicolumn{6}{|c|}{$\begin{array}{c}\text { Men } \\
(\mathrm{N}=5,703)\end{array}$} \\
\hline & \multicolumn{3}{|c|}{ Without MCC } & \multicolumn{3}{|c|}{ With MCC } & \multicolumn{3}{|c|}{ Without MCC } & \multicolumn{3}{|c|}{ With MCC } \\
\hline & \multicolumn{3}{|c|}{$\mathrm{N}=3,683(71 \%)$} & \multicolumn{3}{|c|}{$\mathrm{N}=1,518(29 \%)$} & \multicolumn{3}{|c|}{$\mathrm{N}=3,629(64 \%)$} & \multicolumn{3}{|c|}{$\mathrm{N}=2,074(36 \%)$} \\
\hline & HR & $95 \% \mathrm{CI}$ & P-value & HR & $95 \% \mathrm{CI}$ & P-value & HR & $95 \% \mathrm{CI}$ & P-value & HR & $95 \% \mathrm{CI}$ & P-value \\
\hline \multicolumn{13}{|l|}{ Heart rate $(1 / \mathrm{min})$} \\
\hline $\mathrm{QRS} \geq 110 \mathrm{~ms}$ & 1.2 & $0.4-3.7$ & 0.783 & 0.4 & $0.1-1.4$ & 0.152 & 1.1 & $0.7-1.9$ & 0.608 & 1.3 & $0.9-1.8$ & 0.151 \\
\hline $\mathrm{QTc} \geq 470 / 450 \mathrm{~ms}^{*}$ & 1.3 & $0.7-2.4$ & 0.413 & 1.3 & $0.8-2.2$ & 0.348 & 1.1 & $0.6-2.1$ & 0.657 & 1.2 & $0.9-1.7$ & 0.276 \\
\hline ER & 0.4 & $0.1-1.0$ & 0.046 & 0.7 & $0.4-1.2$ & 0.218 & 1.1 & $0.6-1.9$ & 0.843 & 1.3 & $0.8-1.9$ & 0.278 \\
\hline
\end{tabular}




\begin{tabular}{|c|c|c|c|c|c|c|c|c|c|c|c|c|}
\hline Inferolateral T- & 1.3 & $0.4-4.1$ & 0.638 & 1.1 & $0.4-3.0$ & 0.821 & 3.4 & $1.5-7.8$ & 0.004 & 2.1 & $1.1-4.1$ & 0.027 \\
\hline fQRS & 1.0 & $0.8-1.3$ & 0.993 & 1.0 & $0.8-1.2$ & 0.793 & 1.1 & $0.8-1.4$ & 0.734 & 1.1 & $0.9-1.3$ & 0.324 \\
\hline Anterior & 1.3 & $0.7-2.4$ & 0.338 & 1.0 & $0.6-1.6$ & 0.884 & 1.1 & $0.6-2.0$ & 0.755 & 1.2 & $0.8-1.9$ & 0.432 \\
\hline Inferior & 1.0 & $0.7-1.3$ & 0.940 & 0.9 & $0.7-1.2$ & 0.484 & 1.1 & $0.8-1.4$ & 0.675 & 1.1 & $0.9-1.3$ & 0.452 \\
\hline Lateral & 0.9 & $0.2-3.6$ & 0.875 & 1.4 & $0.5-3.9$ & 0.480 & 1.5 & $0.6-4.1$ & 0.411 & 2.5 & $0.9-6.7$ & 0.072 \\
\hline LVH & 1.2 & $1.0-1.6$ & 0.113 & 1.5 & $1.2-1.9$ & $<0.001$ & 1.2 & $0.9-1.5$ & 0.228 & 1.0 & $0.8-1.2$ & 0.983 \\
\hline Pathological Q- & 1.7 & $0.4-7.4$ & 0.489 & 1.2 & $0.5-2.9$ & 0.741 & 3.2 & $1.1-9.6$ & 0.034 & 3.4 & $1.9-5.9$ & $<0.001$ \\
\hline \multicolumn{13}{|l|}{ waves } \\
\hline Atrial & 16.5 & $3.6-74.7$ & $<0.001$ & 0.0 & $0.0-[$ & 0.982 & 6.2 & $1.5-25.6$ & 0.012 & 5.3 & $1.7-16.4$ & 0.004 \\
\hline \multicolumn{13}{|l|}{ fibrillation/flutter } \\
\hline Left bundle branch & 0.5 & $0.1-3.5$ & 0.480 & 0.0 & $0.0-[$ & 0.922 & 1.2 & $0.2-8.3$ & 0.893 & 3.1 & $1.1-8.2$ & 0.027 \\
\hline \multicolumn{13}{|l|}{ block } \\
\hline Right bundle & 1.1 & $0.2-8.1$ & 0.898 & 0.9 & $9.2-3.5$ & 0.843 & 0.0 & $0.0-[$ & 0.930 & 0.9 & $0.3-2.8$ & 0.862 \\
\hline branch block & & & & & & & & & & & & \\
\hline
\end{tabular}




\footnotetext{
*QTc cutoff point 470ms for women and 450ms for men. Statistical analysis was performed using Cox regression analysis. Adjustments for age, BMI, smoking, diastolic blood pressure, prior cardiac disease and medication for arterial hypertension. Significant differences $(P<0.05)$ between subjects with and without hospitalization for HF highlighted in bold. BMI = body mass index; $C I=$ confidence interval; $E C G=$ electrocardiographic; ER = early repolarization with horizontal or descending ST segment; $f Q R S=$ fragmented $Q R S$ complex; HF = heart failure; HR = hazard ratio; LVH = left ventricular hypertrophy; MCC = morbus cordis coronarius; $Q T c=$ corrected $Q T$ time.
} 